\title{
A Co-evolutionary Perspective on Business and IT Alignment: A Review and Research Agenda
}

\author{
Mengmeng Zhang \\ Science and Technology on \\ Information Systems \\ Engineering Laboratory, \\ National University of \\ Defense Technology \\ mxz391@case.edu
}

\author{
Honghui Chen \\ Science and Technology on \\ Information Systems \\ Engineering Laboratory, \\ National University of \\ Defense Technology \\ chh0808@gmail.com
}

\author{
Kalle Lyytinen \\ The Weatherhead School of \\ Management, \\ Case Western Reserve \\ University, \\ kalle@case.edu
}

\author{
Xinyu Li \\ The Weatherhead School of \\ Management, \\ Case Western Reserve \\ University, \\ xx1691@case.edu
}

\begin{abstract}
Business and IT Alignment (BITA) has received a growing attention during the last decades. Due to increasing environmental and organizational complexities, a co-evolutionary perspective has emerged recently to understand and to control the dynamics in BITA. The Business and IT Co-evolution (BITC) aims to coordinate business and IT through continuous adaptation and learning. A series of BITC studies have been conducted since the 2000s. This study provides an organized review of the current knowledge of this area. Its contribution is threefold: 1) organizing extant literature on BITC, 2) revealing knowledge gaps, and 3) proposing a research agenda.
\end{abstract}

\section{Introduction}

Business and IT Alignment (BITA) persists among the top-ranked concerns of business and IT executives [1-4]. In spite of a vast amount of BITA research, several limitations exist. For example, the research falls short to address increasing environmental dynamics, because BITA is usually studied in the region of "order" rather than "emergent complexity" [5-6]. In addition, the research is often seen unrealistic because it is typically viewed as a formal top-down process without analyzing bottom-level behaviors [7-8]. Furthermore, plenty of the research examines BITA only at a single dimension or on a single level, and thus fails to consider the alignment in a holistic way [2][9]. These limitations are largely caused by increasing external and internal complexities of organizations' environments [10-11]. Therefore, traditional BITA research demands a new perspective [12].

Recently, a co-evolutionary perspective has been proposed to address the above limitations [5][12-13]. Under this perspective, multi-level, multi-directional, non-linear, and feedback-based relationships between business and IT are controlled through continuous adaptation and learning [5][7][14]. The Business and IT Co-evolution (BITC) forms "a co-evolutionary process that reconciles top-down 'rational designs' and bottom-up 'emergent processes' of coherently interrelating all components of the Business/IS relationships in order to contribute to an organization's performance over time" [5][15]. BITC has been a growing concern for researchers and practitioners alike.

To the best of our knowledge, there is a dearth of a thorough but dedicated review of BITC. Previous BITA reviews have not adequately discussed the dynamic alignment in a higher region of complexity. As a new perspective, BITC goes beyond traditional BITA assumptions and challenges prior methods and models. Discussions of BITC in the extant literature are disconnected. A large number of BITC research focuses on the clarification of its definition and the description of the phenomenon [8][12]. While the effects of environmental and organizational factors on BITC and the outcomes of BITC on performance have not been validated holistically. In addition, compared with the extensive research on BITC conceptualization, the practical research of BITC is scarce [13].

To advance future research, our goal in this paper is to systematically integrate prior BITC research across different foci. First, we aim to classify extant BITC literature by analyzing the environmental and organizational changes influencing the BITC, as well as the associated performance. Second, we identify gaps from the analyzing results and propose future research directions. The paper is organized as follows. The subsequent section explains the theoretical background and derives an analytical framework. We next describe the research method. Then, we present a synthesis of the current knowledge base. This is followed by an outline of identified research gaps and a 
research agenda on BITC. The paper concludes with contributions and limitations of this research.

\section{Background and research framework}

BITA research has evolved enormously since Henderson and Venkatraman proposed a strategic alignment model in 1993 [1]. BITA has been defined variously as the degree of fit and integration between an organization's business strategy, IS/IT strategy, business structure, and IS/IT infrastructure [1-2]. It persists among the top-ranked concerns of business and IT executives as a crucial practice to maximize return value on IT investment and to improve overall organizational performance [16]. Literature reviews of BITA have often discussed BITA definitions, measures, levels, and dimensions [2][17-19]. Basically, these reviews identified two perspectives regarding the nature of alignment: alignment as an end state and alignment as an ongoing process [2]. The first focuses on the antecedents, measures, and outcomes of BITA [20-22]. The second refers to a sustainable alignment, which requires continuous business and IT management [23]. Scholars tend to capture dynamic BITA in equilibria [23-26], and continuously attempt to combine the above two perspectives [2].

Currently, complexity of an organization is increased by the "dancing rugged" market environment [12], pervasive digital technologies [27], and complex relationships between business and IT [5][28]. The increasing complexity poses challenges for traditional BITA research. Achieving a higher level of BITA doesn't always guarantee an increase in organizational performance, and occasionally may even be adverse [29-31]. It is clear that the sustainable BITA process is shifting away from equilibrium and embracing "emergent complexity" [6][12-14]. As the capability framework proposed by Tanriverdi [6] argued, a coevolution strategy should be chosen when an organization is in the region of emergent complexity. This strategy views business and IT elements as a holistic ecosystem, acknowledging the non-linear relationships of business and IT. To analyze this ecosystem, El Sawy [32] provides a configurational model to explain the complex relationships of business and IT and to explore suitable combinations of them. In addition, Benbya displays the relationships into a three-level co-evolutionary model (strategic level, operational level, individual level), and depicted its multi-level effects, multi-directional causalities, nonlinearity, and positive feedback [5]. In order to survive in turbulent environments, organizations are recommended adopting this strategy to tame deviations through adaptation, improvisation, or self-organization, instead of implementing a fixed solution [5-8]. For example, a circular co-evolutionary model provided by Peppard [33] represents the key components in the process of BITC. Amarilli has developed a coevolutionary model which embodies the controlling parameters, enablers, and dynamic actors of BITC [34]. Perrard [14] explores the feedback relationships of various influencing factors of co-evolution through a systems dynamics model. All of these models aim to identify key co-evolutionary mechanisms and to control the complex organizations proactively.

According to the above explanation, understanding BITC's antecedents and consequences is imperative. Drawing on the above explanations, BITC research is largely motivated by a combination of environmental dynamics and organizational complexity [10-11]. For example, the market environment is widely shaped by pervasive IT innovations, which give rise to complex phenomena such as two-sides market [35], platformbased architecture [36-38], and IT ecosystem [37][39]. In addition, the internal management activities become elusive because of technological drifting [7], inertia [30-31], and other unforeseen events [5]. All of the above phenomena impose emergent changes influencing business and IT in different levels. Therefore, organizations should integrate both topdown formal control and bottom-up emergent adaptation to embrace the unpredictable changes, in order to improve the performance outcomes [5][12]. At the same time, the BITC could conversely shape the organizational structures [5] and influence the external market environments [40]. To assess the above aspects of BITC, we adopt an analytical framework based on prior related studies [40-42]. The framework is visualized in Figure 1. Among others, "Environmental changes and conditions" refers to the exogenous factors such as component innovations [43], architectural innovations [43], or dynamic market requirements [44]. "Organizational changes and conditions" includes the internal requirements and preconditions supporting the needs for changes. "Organizational performance" refers to the outcome effects of BITC. The relationships explained in the above are incorporated into the framework.

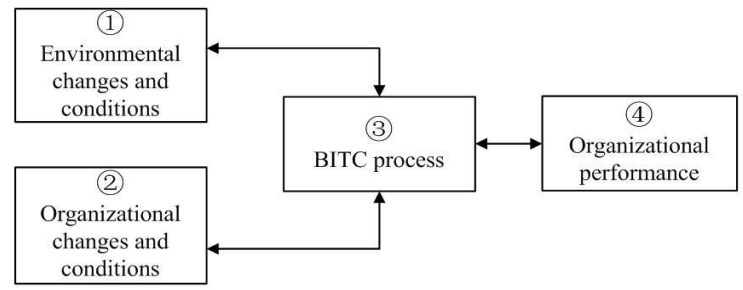

Figure 1. An analytical framework on BITC research 


\section{Research method}

This study analyzes the state of BITC research as reflected in the aforementioned analytical framework. The literature analysis is carried out according to prior recommendations of literature reviews [45-46].

Initially, papers addressing the BITC issue are identified within the journals suggested by the Senior Scholar Consortium of the Association for Information Systems (AIS) as top journals in the field, including European Journal of IS, IS Journal, IS Research, Journal of the AIS, Journal of Information Technology, Journal of MIS, Journal of Strategic IS, and MIS Quarterly. We still consider several IS conferences in the searching process to enrich the research body. The Hawaii International Conference on System Science, International Conference on Information Systems, and European Conference on Information Systems are selected in this paper. We also analyze other important articles we have identified in the process of searching.

The identification of the literature starts with a keyword search. We search for the journal and conference papers that comprises alignment terms (e.g., "IS alignment", "strategy alignment") and complexity terms (e.g., "complexity", "co-evolution", "dynamics") in its title or abstract. We have discovered 96 articles in this process. Furthermore, we eliminate articles that don't involve the main contents in our analytical framework after reading the papers, which resulting in a number of 42 papers to review in this study.

We primarily classify the articles with the analytical framework, focusing on each of the essential elements and the relations between. Furthermore, we also organize them based on several other dimensions. The first concerns the types of research frameworks (Theoretical, Conceptual, Practical) that scholars use to understand and describe BITC. The theoretical framework is formulated using established, coherent explanations of relationships between business and IT (e.g. activity theory [47]). The conceptual framework is put forward using an array of constructs, such as the alignment concepts on the strategic level (business strategy and IS strategy), operational level (business department and IS department), and individual level (IS and users) [5]. These three levels are often applied to formulate BITC, and thus are treated as three categories of analytical levels. The practical framework is articulated by synthesizing findings from practitioners' insights [14]. To validate proposed frameworks, scholars employee qualitative or quantitative methods. The methodology used is identified as one dimension in this paper. In addition, we summarize four phases of BITC research. A "Sensing" phase aims to identify the presence of BITC phenomenon and to bring it to the attention of researchers [6]. A "Sensemaking" phase interprets the definitions and features of the BITC process [6]. An "Improving" phase focuses on favoring the BITC process by developing specific governance principles [6]. And an "Implementing" phase mainly concerns how to control organizations' BITC process and to improve the performance in practice [13].

In brief, we organize the 42 articles using the framework in Figure 1, and also categorize them by applied research frameworks, levels of analysis, methodologies used, and the study phases. Noted that our classification is not necessarily mutually exclusive within some of the dimensions. Therefore, a paper may involve multiple foci, levels, and phases.

\section{Results}

The results demonstrate a growing interest of BITC research in recent years as $72 \%$ of the studies have been published after 2010. Detailed results are summarized in Table 1. The following section presents an in-depth description of the findings, organized based on our analytical framework in Figure 1.

\subsection{Environmental changes and conditions}

In general, elements from both IT and business environments represent as external factors to motivate BITC research. Currently, organizations operate in a world that is increasingly permeated with digital technologies such as big data and cloud computing [27]. The affordances of digital technologies create innovations characterized by convergence and generativity [27]. The pervasive digital innovations are radically changing the nature of products and services [37]. Embracing digital technology platforms (e.g., Apple's iOS) [36-38] and IT ecosystems (e.g., digital music ecosystem) [39] is one of the important outcomes of digital innovations. As a result, the whole IT environment becomes volatile and unpredictable. Many analysts have recognized that it is difficult to predict future technological advances and to make decision about IT investments and planning [39].

IT innovations impose disruptive effects on organizations' business environment. While digitizing business processes, products, and services, organizations are forced to reposition their competitive strategies and corporate strategies [12]. Scholar have introduced several terms including "business ecosystems" [44] and "complex adaptive business systems" [12], in order to describe the complexity in business environment [12]. As Vidgen and Wang argued [44], business management in an organization has transferred to the business ecosystem in order to 
adapt to the changing business circumstances. In summary, the business environment has toppled the traditional assumptions of partnerships, supply chains, and inter-firm collaborations. Firms are facing significant survival and performance challenges.

In such dynamic IT and business environments, an organization's complexity increases as its diversity, adaptiveness, connectedness, or mutual dependencies of product markets increase [12]. As a consequence, the operations of organizations deviate from the equilibria and exhibit characteristics such as emergence, self-organization, surprises, disruptions, digital transformations, and even irreversible discontinuities [6]. Organizations are challenging to co-evolve with complex market positions [5][12]. To address this issue, the relationship of business and IT should be bridged in an ecosystem instead of being apart [44]. Studies on digital business strategy [40-42] also argue that the business strategy and IT strategy should be fused to fully take advantage of the pervasive IT innovations. Therefore, the coevolutionary perspective was introduced to help increase the chance of survival of organizations in such environments. On a macro-level, the organizations coevolve with each other in the environments; and on a micro-level, business and IT co-evolve within an organization. We identify that the discussions of the environmental dynamics and its relations with BITC are often conducted in a "Strategic" level with a "Conceptual" or "Theoretical" framework. These papers are likely to use "Non-empirical" methods to sense and to define the BITC phenomenon.

\subsection{Organizational changes and conditions}

From another side, BITC research is driven by emergent organizational deviations from intended strategies or plans. These internal deviations include but not limit to business strategy changes [12][48], IT changes [49-52], inertia [30-31][53], and other unpredictable events [5][53]. For example, to survive in the dynamic business environment, an organization needs to continuously reposition its competitive strategies and corporate strategies, in order to seek for profitable product-market niches [12]. A Chinese company transformed its strategy intent from "imitation" to "focus", in order to adapt for China's access to WTO [48]. In addition, the pervasive digital innovations force organizations to engage or develop new IT systems or services. Several complex issues, such as legacy systems [49], IS engagement [50-51], and IS development [52], may emerge in this process. Furthermore, organizational inertia sometimes occurs to impede the execution of plans. It refers to organizations' tendency to maintain stability of their arrangements such as strategy and structure in spite of environmental changes [31][54]. Inertia may be caused by short-term success, but would lead to sub-optimal conditions in long-term, especially in markets with rapid change. Scholars argue that inertia is the main reason for the paradox between BITA and organizational performance [29-31]. Additionally, there are several other kinds of organizational deviations, such as resource shortages [53][55], human errors [5], and political machinations [53].

We consider several preconditions supporting the needs for changes and improvising solutions. Changing the understanding of IT is one to handle the potential deviations in an organization. Given the powerful benefits of IT on any organization's performance, it is imperative to view digital IT capabilities as inherent elements of planning business strategies and plans. As Bharadwaj argued [42], it is time to rethink the role of IT strategy, from that of a functional-level strategy to one that reflects a fusion between IT strategy and business strategy. Not just at the strategic level, IT should also be embedded at the operational level and individual level [5]. As a result, the gap between business and IT should be filled over time, and ultimately the two form a holistic and complex system.

Suitable organizational structuring is another precondition to address potential changes. It facilitates communication and knowledge sharing between business and IT actors, and helps decision making and executing. As Peppard argued, the desire for communication, mutual trust, and collaboration will all be improved with a proper organizational model [14], which helps avoid misunderstandings between business and IT, overcome inertia, and consequently tame emergent deviations [14][56]. Multiple organizational types, such as centralized, decentralized, and hybrid, have been discussed in the literature [23][56].

Applying modular design to IS architecture is another precondition [5][15][52]. Conforming to the "nearly decomposable" and "loose coupling" rules [5], modular design demands a system's components to be separated and recombined, such as the service-oriented architecture. Modular design represents the ability to easily reconfigure components by minimizing interdependencies among modules [5]. It helps the IS architecture react to changes in a timely way [5], and reprograms different kinds of IT innovations [57].

According to Table 1, the discussions of organizational changes and the relations with BITC have received a lot of research. Most of them has analyzed multiple levels of alignment with "Conceptual" or "Theoretical" frameworks. They tend to use "Non-empirical" or "Qualitative" methods to define the BITC and to explain the phenomenon. 
Table 1. Classification matrix of BITC literature

\begin{tabular}{|c|c|c|c|c|c|c|c|c|c|c|c|c|c|c|c|c|c|c|c|c|c|c|c|}
\hline \multirow[b]{2}{*}{ Literature } & \multicolumn{10}{|c|}{ Focus } & \multicolumn{3}{|c|}{ Framework } & \multicolumn{3}{|c|}{ Level } & \multicolumn{3}{|c|}{ Method } & \multicolumn{4}{|c|}{ Phase } \\
\hline & (1) & (2) & (3) & (4) & $\begin{array}{l}\ominus \\
\dot{v} \\
(0)\end{array}$ & $\begin{array}{l}(0) \\
\dot{v} \\
\ominus\end{array}$ & $\begin{array}{l}\text { (1) } \\
\dot{1} \\
\text { (0) }\end{array}$ & $\begin{array}{l}\text { (0) } \\
\dot{1} \\
\text { (N) }\end{array}$ & $\begin{array}{l}(0) \\
\dot{1} \\
\oplus\end{array}$ & $\begin{array}{l}\oplus \\
\stackrel{\oplus}{V} \\
\text { (i) }\end{array}$ & 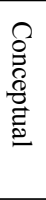 & 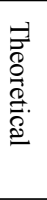 & 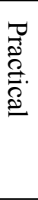 & 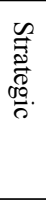 & $\begin{array}{l}0 \\
\stackrel{0}{0} \\
0 \\
0 \\
0 \\
0 \\
0 \\
0 \\
0\end{array}$ & 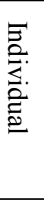 & 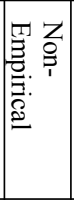 & & 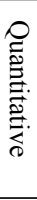 & 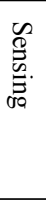 & 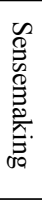 & 志 & 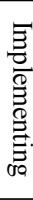 \\
\hline [3] & & & & $\bullet$ & & & & & $\bullet$ & & & $\bullet$ & & $\bullet$ & & & & & $\bullet$ & & $\bullet$ & & \\
\hline [4] & & & & $\bullet$ & & & & & $\bullet$ & & $\bullet$ & & & $\bullet$ & $\bullet$ & $\bullet$ & & & $\bullet$ & & $\bullet$ & & \\
\hline [5] & & $\bullet$ & $\bullet$ & & & & $\bullet$ & $\bullet$ & & & $\bullet$ & & & $\bullet$ & $\bullet$ & $\bullet$ & $\bullet$ & & & $\bullet$ & $\bullet$ & $\bullet$ & \\
\hline [6] & $\bullet$ & & $\bullet$ & & $\bullet$ & & & & $\bullet$ & & 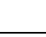 & $\bullet$ & & $\bullet$ & $\bullet$ & $\bullet$ & $\bullet$ & & & & $\bullet$ & $\bullet$ & \\
\hline [8] & & $\bullet$ & $\bullet$ & & & & $\bullet$ & & & & 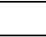 & $\bullet$ & & & $\bullet$ & $\bullet$ & & $\bullet$ & & $\bullet$ & & & \\
\hline [12] & $\bullet$ & & $\bullet$ & $\bullet$ & $\bullet$ & & & & $\bullet$ & & $\bullet$ & & & $\bullet$ & & & $\bullet$ & & & $\bullet$ & & & \\
\hline [13] & $\bullet$ & . & $\bullet$ & & $\bullet$ & & & $\bullet$ & & & $\bullet$ & & & & $\bullet$ & $\bullet$ & $\bullet$ & & & $\bullet$ & $\bullet$ & & \\
\hline [14] & & $\bullet$ & $\bullet$ & 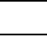 & & & $\bullet$ & $\bullet$ & & & 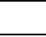 & & $\bullet$ & $\bullet$ & $\bullet$ & & 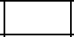 & $\bullet$ & & $\bullet$ & $\bullet$ & $\bullet$ & \\
\hline [15] & 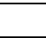 & & $\bullet$ & $\bullet$ & & & & & $\bullet$ & & $\bullet$ & & & 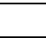 & & $\bullet$ & - & & $\bullet$ & & & $\bullet$ & $\bullet$ \\
\hline [28] & & $\bullet$ & $\bullet$ & & & & & $\bullet$ & & & $\bullet$ & & & & & $\bullet$ & $\bullet$ & & & & $\bullet$ & & \\
\hline [29] & $\bullet$ & $\bullet$ & & $\bullet$ & & & & & $\bullet$ & & $\bullet$ & & & $\bullet$ & & & & & $\bullet$ & & $\bullet$ & & \\
\hline [30] & $\bullet$ & $\bullet$ & & $\bullet$ & & & & & $\bullet$ & & $\bullet$ & & & $\bullet$ & & & 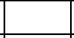 & & $\bullet$ & - & & & \\
\hline [31] & $\bullet$ & $\cdot$ & 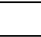 & $\bullet$ & & & & & $\bullet$ & & $\bullet$ & & & $\bullet$ & 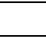 & & . & & $\bullet$ & $\bullet$ & - & & \\
\hline [32] & $\bullet$ & $\bullet$ & 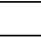 & & & & & & $\bullet$ & & $\bullet$ & & & $\bullet$ & 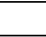 & & $\bullet$ & & & $\bullet$ & $\bullet$ & & \\
\hline [33] & & 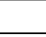 & $\bullet$ & & $\bullet$ & & & & 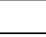 & & 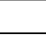 & $\bullet$ & & $\bullet$ & 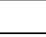 & & $\bullet$ & & & $\bullet$ & $\bullet$ & & \\
\hline [34] & 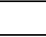 & 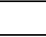 & $\bullet$ & & & & & $\bullet$ & 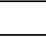 & & $\cdot$ & & & 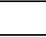 & $\bullet$ & $\bullet$ & 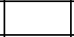 & $\bullet$ & & 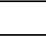 & $\bullet$ & $\bullet$ & $\bullet$ \\
\hline [38] & $\bullet$ & $\bullet$ & & 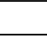 & 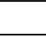 & & & & $\bullet$ & & $\bullet$ & & & 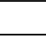 & $\bullet$ & $\bullet$ & $\bullet$ & & & 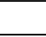 & $\bullet$ & $\bullet$ & \\
\hline [40] & - & - & & $\bullet$ & - & $\bullet$ & - & - & - & $\bullet$ & $\cdot$ & & & $\cdot$ & 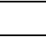 & & - & & & - & $\cdot$ & & \\
\hline [42] & $\bullet$ & $\bullet$ & 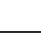 & 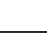 & $\bullet$ & & - & & $\bullet$ & & $\cdot$ & & & $\bullet$ & 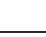 & & $\bullet$ & & & - & & - & \\
\hline [43] & $\bullet$ & 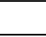 & 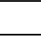 & $\bullet$ & . & & 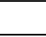 & 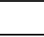 & & & 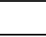 & $\bullet$ & & $\bullet$ & $\bullet$ & $\bullet$ & 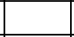 & & $\bullet$ & & & $\bullet$ & \\
\hline [44] & & $\bullet$ & $\bullet$ & & & & $\bullet$ & $\bullet$ & & & $\bullet$ & & & & $\bullet$ & $\bullet$ & $\bullet$ & & & $\bullet$ & $\bullet$ & & \\
\hline [47] & & $\bullet$ & $\bullet$ & & . & & $\bullet$ & & & & & $\bullet$ & & 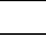 & $\bullet$ & $\bullet$ & & $\bullet$ & & & $\bullet$ & $\bullet$ & \\
\hline [48] & $\cdot$ & 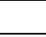 & $\bullet$ & & $\bullet$ & $\bullet$ & & $\bullet$ & $\bullet$ & $\bullet$ & & $\bullet$ & & $\bullet$ & $\bullet$ & & & $\cdot$ & & . & $\bullet$ & & \\
\hline [49] & & $\bullet$ & $\bullet$ & & & & & $\bullet$ & & & & $\bullet$ & & & $\bullet$ & $\bullet$ & & $\cdot$ & & $\bullet$ & . & $\bullet$ & - \\
\hline$[50]$ & & $\bullet$ & $\bullet$ & & & & $\bullet$ & & & & & $\bullet$ & & & $\bullet$ & $\bullet$ & & $\bullet$ & & & $\bullet$ & & \\
\hline [51] & & $\bullet$ & $\bullet$ & & & & $\bullet$ & & & & & $\cdot$ & & & $\bullet$ & $\bullet$ & & $\bullet$ & & 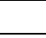 & $\bullet$ & & \\
\hline [52] & & $\bullet$ & $\bullet$ & & . & & $\bullet$ & $\bullet$ & & & & $\bullet$ & & & 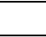 & $\bullet$ & $\bullet$ & & & $\bullet$ & $\bullet$ & $\bullet$ & \\
\hline [53] & & - & 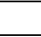 & & $\bullet$ & & - & & $\bullet$ & & & $\cdot$ & & $\bullet$ & - & . & $\bullet$ & & & & $\bullet$ & $\bullet$ & \\
\hline [56] & & $\cdot$ & $\cdot$ & & 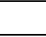 & & $\bullet$ & $\cdot$ & & & & & $\bullet$ & $\cdot$ & $\bullet$ & $\bullet$ & & $\bullet$ & & & 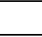 & $\bullet$ & \\
\hline [58] & & $\cdot$ & $\cdot$ & & $\cdot$ & & $\bullet$ & & & & $\bullet$ & . & & 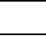 & $\bullet$ & $\cdot$ & $\cdot$ & & & $\cdot$ & $\bullet$ & & \\
\hline [59] & & & $\bullet$ & & & & $\bullet$ & $\bullet$ & $\bullet$ & & & $\bullet$ & & & & $\bullet$ & & $\bullet$ & & $\bullet$ & $\bullet$ & & \\
\hline [62] & $\bullet$ & $\bullet$ & & & $\bullet$ & & $\bullet$ & & $\bullet$ & & & $\bullet$ & & $\bullet$ & & & & $\bullet$ & & & $\bullet$ & $\bullet$ & $\bullet$ \\
\hline [63] & $\bullet$ & $\bullet$ & $\bullet$ & & & & $\bullet$ & & $\bullet$ & & • & & & $\bullet$ & & & & $\bullet$ & & $\bullet$ & $\bullet$ & & \\
\hline [64] & $\bullet$ & $\bullet$ & & & . & & & & $\bullet$ & & & $\bullet$ & & $\bullet$ & & & & $\bullet$ & & & 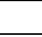 & $\bullet$ & \\
\hline [65] & $\bullet$ & $\bullet$ & & & $\cdot$ & & $\bullet$ & & & & & $\bullet$ & & $\bullet$ & & & $\bullet$ & & & & $\bullet$ & $\bullet$ & \\
\hline [66] & & $\bullet$ & & & & & $\bullet$ & & & & & & $\bullet$ & & $\bullet$ & & $\bullet$ & & & $\bullet$ & & $\bullet$ & \\
\hline [67] & & & & $\bullet$ & $\cdot$ & & $\bullet$ & & $\bullet$ & & & $\bullet$ & & $\bullet$ & & & & & - & & $\bullet$ & & \\
\hline [69] & $\bullet$ & & $\bullet$ & $\bullet$ & $\bullet$ & & & & $\cdot$ & $\bullet$ & $\bullet$ & & & $\bullet$ & $\bullet$ & & $\bullet$ & & & & $\bullet$ & & \\
\hline$[72]$ & & $\bullet$ & 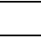 & & $\cdot$ & & $\bullet$ & & & & & & $\bullet$ & $\bullet$ & & & & $\bullet$ & & $\bullet$ & & & \\
\hline [73] & & & $\bullet$ & & & & $\bullet$ & & & & $\bullet$ & & & $\bullet$ & $\bullet$ & $\bullet$ & & & $\bullet$ & & $\bullet$ & & \\
\hline$[74]$ & & & $\bullet$ & & & & $\bullet$ & & & & $\bullet$ & & & & $\cdot$ & & $\bullet$ & & & & $\bullet$ & & \\
\hline$[75]$ & $\bullet$ & & & & $\bullet$ & & & $\bullet$ & & & & $\bullet$ & & & $\bullet$ & & $\bullet$ & & & $\bullet$ & & $\bullet$ & \\
\hline $\mathrm{N}=42$ & 18 & 26 & 24 & 11 & 15 & 2 & 22 & 13 & 20 & 3 & 20 & 18 & 4 & 25 & 22 & 20 & 19 & 14 & 9 & 20 & 29 & 17 & 4 \\
\hline
\end{tabular}

\subsection{BITC process}

Drawing on the above explanations, the external and internal complexities of an organization give rise to emergent changes that create misfits within business and IT. In this case, top-down control and bottom-up adaptation should be integrated to tame the deviations and to maintain organizational performance [5][53][58]. Scholars have attempted to introduce relational theories to describe the BITC process. For example, as the evolutionary theory of organizations can draw on Darwinian models of natural selection, three essential generative principles including Variation, Selection, and Retention are applied to detect variations in the alignment, to choose profitable solutions, and to repeat use for improvements [50-51][59]. In addition, an activity system theory is considered to sense the contradictions among different actors and then to conduct root-cause analyses in the system evolutionary process [47]. Furthermore, Teece's dynamic capability framework [60-61] has been applied to explain the BITC process [62-65], with the argument that the 
continuous alignment is a dynamic capability. This framework includes three broad capabilities (SensingSeizing-Transforming). Specific actions, such as decision making and resource allocating, are required to link with each stage. Scholars argued that the dynamic BITC capability can be enacted through the sensing, seizing, and transforming capacities and their attendant aligning actions [62][64]. Table 1 indicates that the BITC process has been often described with a "Theoretical" or "conceptual" framework.

Governance principles are either embedded in the above theories, or individually proposed in the literature. The governance principles ensure adaptive outcomes for taming emergent deviations [5]. For example, Benbya and McKelvey introduce five first Principles of Efficacious Adaptation to describe how BITC can be favored [5], of which, Nassim and Robert validate three through an open source system case [15]. Several principles are taken as examples here. The principle of "Adaptive tension" [5][15][47][52] refers to applying tensions when and where needed, such as sensing misalignment symptoms, mitigating inertia, or imposing interactions among actors. The "Communication" principle [7-8][14][28][34][66] recommends cultivating the communications among business and IT roles. It helps share domain knowledge, promote mutual trust, and form a suitable organizational structure. The "Resource allocation" principle [62-65] tends to re-configure existing resources or to build new resources to supplement current gaps in the organizational resource base. The principle of "Experimenting and learning" [6][14][58] applies experimental mechanisms to emergent deviations and learns from their reactions. Because BITC is a "wicked problem" [6] and the root causes of deviations are entangled, the deviations cannot be "solved" but should be "tamed" [6]. Overall, governance principles are proposed to improve the BITC process. They are frequently explained with the "Non-empirical" or "Qualitative" method, but have rarely tested with the "Quantitative" method [15].

Compared with the last two subsections, the BITC process can conversely influence the external environment and internal organization. As El Sawy [32] argued, the market environment can be shaped by the combination of IT systems and their strategic capabilities. Markets are confronted with the organizations' evolutionary trajectory, which will necessitate new forms of partnerships and may seek new dynamic capabilities [38]. On the other side, all of the business processes [44][48], business structures [48][56], services [49][59], and IT architectures [56][59] in an organization need to be reconsidered in the BITC process. Taking the organization's relations with users as an example, the co-evolution of an investment system and the company can weaken the relationships of analysts and users, and strengthen the users' connections with the company [59]. According to Table 1, the research on these relations focuses less on how BITC influences the external environment.

In addition, studies have also explained and validated alignment's relations with organizational performance, especially by "Quantitative" methods (e.g., structural equation modeling [4][30-31], metaanalysis [3]). In recent years, research has discovered a mix effect between alignment and performance [29-31], and the root cause is human inertia in the social dimension [30-31], which indicates that overcoming human inertia should be an indispensable principle to help control the BITC process.

\subsection{Organizational performance}

Any alignment of business and IT is deemed to facilitate overall organizational performance [20-21]. Measuring the performance outcomes is a major topic in alignment related research [2]. The performance outcomes are varied but not limited to agility [29-31], market growth [48][67], cost control [62][67], and financial performance [4][15][48][67].

Traditionally, scholars are likely to evaluate the maturity level of BITA with deterministic models (e.g., matching and moderation approach, profile deviation approach, and scoring approach) [1][20-21], which view alignment as an end state. Several optimized methods (e.g., maturity model [20-21], IT governance model [55]) integrating the end state and the process still locate BITA in the "Order" region [23][68], instead of considering it "on the edge of chaos" [6][12]. Due to the non-linearity between business and IT, a thorough measurement of organizational performance on current alignment is difficult and dearth. To deal with this issue, scholars recommend considering business and IT elements in a holistic way [6][12][32], which means the relations of business and IT should not be divided but be fused [44]. El Sawy has introduced a configuration method to evaluate the holistic influence of them [32]. The configuration method views system elements as combinations, which are evaluated as a holistically integrated pattern accommodating complex interconnectedness of multiple elements, nonlinearities, and discontinuities [32]. According to Table 1, the discussions of "Organizational Performance" mainly focus on the "Sensemaking" phase, through explaining the firm's performance with BITC process. The corresponding frameworks are "Conceptual" or "Theoretical".

Performance outcomes may pose new requirements for the BITC process, which in turn influence the environment and organization [40][48][69]. For 
example, the market performance of IT-enabled business models will impose adaptations of B2B IT capabilities and their strategy intents [69]. The results in Table 1 show the research on this relation is scarce.

\section{Discussion and research agenda}

We have analyzed the current BITC knowledge base in the last section. Through deeply discussing results of the five dimensions, we aim to discover the research gaps and to explore possible solutions in this section.

We can induce that the majority of extant research focuses on the conceptualization of BITC based on the dimensions of "Focus" and "Phase". Relational theories have been introduced in this process, such as the complex adaptive system theory [50-51], control theory [58], institutional theory [53], and configuration theory [32]. These theories are dispersed in the literature and address the BITC issues finitely. Additionally, according to the results of the "Level" dimension, seldom paper analyzes the three alignment levels holistically. Furthermore, though some scholars have discussed the relationship between alignment and performance, rare has distinguished the differences of performance between traditional alignment and BITC. The traditional alignment supports to improve performance with sustainable competitive strategies. While BITC requires more dynamics. Short-term misalignment or low-performance may be accepted in this region. As Baker argued, organizations should takes advantage of beneficial effects that deviations offer, even if a temporary misalignment may occur [53]. Tanriverdi claimed that a firm can pursue temporary advantages over time [12]. Combining these two kinds of competitive strategies is important to understand alignment and manage performance in the long run. At the same time, most of the scholars have verified positive impacts of BITC on performance, but seldom related to the negative aspects such as the increasing cost of dynamic alignment [49].

Comparatively analyzing the results of the five dimensions, we identify that extant BITC research is unsubstantial to implement the BITC process. Majority of the research tends to explain BITC's motivations and its performance outcomes, instead of testing and controlling the dynamics in practice. "Conceptual" and "Theoretical" frameworks are frequently introduced in the literature. A tremendous gap is determined between academic and practical research [13][34]. To motivate the future practical research in BITC implementation, we will mainly explore the research gaps in this aspect.

The first issue roots in governance principles. Currently, the governance principles are immersed in various articles. They are often used to explain the concept of BITC, but rarely treated as guidelines for practice. In addition, the granularity of principles varies significantly. To deal with this problem, scholars point out that extensive principles [14][34][64][66] and the relationships among them [14][34] need to be determined. Governance principles should be collected with the help of data collection methods such as interviews, oral history, focus groups, and observation [14]. Principles may exist in different alignment levels [5] and dimensions [2][9]. Meanwhile, the principles should be practical enough to be easily applied to real cases. Additionally, causal loop diagrams or influence diagrams [14][53] can determine the relationships of the principles. Understanding the positive or negative relationships of them is beneficial to balance their applications in practice. Besides, the principles should be tested in real cases [15][34]. Traditional alignment mechanisms are not suitable for the BITC case [34]. Overall, through identifying the principles, their correlations, and their roles in real cases, we will know how, where, and when to tame the unintended changes with these principles during the BITC process [6].

The second issue is the adoption of computational models. Scholars argue that the behaviors of complex BITC system are still hard to control with the help of governance principles [66]. Practitioners find hard time to convert the BITC implications into managerial practices [5][13]. Computational models can be used to analyze and validate governance principles. Through simulating the use of principles, and studying the differences in the outcome of the experiments, the models can present an in-depth explanation of BITC [13]. According to Table 1, only a small number has employed computational models, and seldom has conducted quantitative analysis of these models [15]. As Amarilli [34] argued, no studies have been yet carried out using quantitative methods to describe the dynamics of alignment. We deem that the system dynamics models (SDM) and agent-based models (ABM) may be the answers to this problem. The SDM helps capture the dynamic features of complex systems, and understand complexity in focal systems [70-71]. The SDM of BITC can integrate governance principles and their relationships in a causal loop diagram, and analyze the adaptations of emergent behaviors. Peppard [14] and Baker [53] have developed SDMs to describe how governance principles are formed and ruled during the BITC process. They help managers understand dynamic behaviors between IT and business activities, provide evidence of the effects of such interactions, and thereby improve BITC related decision-making. Nevertheless, the system dynamics approach is a high-level method addressing complex behaviors in a holistic way. Individual behaviors in a complex system need to be detected and adapted [66]. 
$\mathrm{ABM}$ is a kind of microscale model that simulate the operations and interactions of multiple agents to recreate and predict the appearance of complex phenomena [28]. As a "bottom-up" modeling method, it describes emergent behaviors on the individual level, and the whole organizational behaviors can emerge as a cumulative outcome of individual behaviors [43]. According to the literature [71], SDM can be integrated with ABM, which involves the top-down control and bottom-up adaptation. In this case, the integrated model will be able to capture real-life phenomena and to generate micro controls for detailed decision-making.

The third problem locates in the practical research of BITC implementation. In view of the above gaps, the academic achievements of BITC have not been transformed into practical applications [13][34]. As Karpovsky and Galliers [66] argued, we still know little about what the organizational actors actually do, on a day-to-day basis, to align IS and related concerns with business. That is the reason why the alignment literature is sometimes criticized for being too conceptual and not reflecting actual practices [7-8] [66]. Therefore, more case studies, especially the longitudinal studies, need to be conducted in the future [31][33][47][64][67]. Practical applications and tools should be introduced [67]. Specifically, practitioners should pay more attention to the combination of traditional alignment and BITC, in order to balance different kinds of order. The complexity region of an organization changes in its evolution process, which forces the practitioners select suitable strategies in each region [6]. In other words, practitioners should differentiate short-term and long-term factors [2], equilibrium and nonequilibrium [5][23], exploitation and exploration [33][43], in order to grasp changes and execute corresponding activities proactively.

In summary, the co-evolutionary perspective of BITA is a new topic in BITA research. We argue that managing and controlling the BITC process in practice is one of the main research gaps in the extant literature. We encourage more future works focusing on this area.

\section{Conclusion}

This paper examines the current research state of BITC. The analysis of 42 articles results in a detailed overview of the environmental and organizational changes influencing the BITC process, and their associated performance outcomes. We indicate knowledge gaps and develop an agenda mainly from governance principles, computational models, and practical studies. Our future research will mainly focus on the practical aspect of BITC implementation.
The analysis outcomes highlight our contributions. With regards to the academic research, this study has conducted a structured description of the current BITC knowledge base and related content elements, as well as an agenda for future research. In view of the practice, we identify that the practical research of BITC is inadequate currently, and we have proposed possible solutions through three aspects.

Nonetheless, as a new research topic, possible relevant publications of BITC may exist in the other research fields (e.g., organization evolution, complexity science). These articles may not be identified through the search terms and sources. We will extend the searching scope to enrich the BITC related research body in the future research.

\section{References}

[1] Henderson, J.C. and Venkatraman, H. Strategic alignment: Leveraging information technology for transforming organizations. IBM Systems Journal 32, 1 (1993), 472-484.

[2] Chan, Y.E. and Reich, B.H. IT alignment: what have we learned? Journal of Information Technology 22, 4 (2007), 297-315.

[3] Gerow, J. E., Grover, V., Thatcher, J. B., and Roth, P. L. Looking toward the future of IT-business strategic alignment through the past: A meta-analysis. MIS Quarterly 38, 4 (2014), 1059-1085.

[4] Luftman, J., Lyytinen, K., and ben Zvi, T. Enhancing the measurement of information technology business alignment and its influence on company performance. Journal of Information Technology 32, 1 (2017), 26-46.

[5] Benbya, H. and McKelvey, B. Using coevolutionary and complexity theories to improve IS alignment: a multi-level approach. Journal of Information technology 21, 4 (2006), 284-298.

[6] Tanriverdi, H. and Lim, S. Y. How to Survive and Thrive in Complex, Hypercompetitive, and Disruptive ecosystems? The Roles of IS-enabled Capabilities. The 38th International Conference on Information Systems Seoul, South Korea (2017), 1-21.

[7] Ciborra, C. From Control to Drift: The Dynamics of Corporate Information Infrastructures, Oxford University Press: Oxford, UK. 2000.

[8] Simpson, J. R., Wilkin, C. L., Campbell, J., Keating, B. W., and Moore, S. "Iterate wildly": is User-Centred Design and Prototyping the Key to Strategic Alignment? The 24th European Conference on Information Systems Istanbul, Turkey (2016), 1-12.

[9] Schlosser F, Wagner HT, and Coltman T. Reconsidering the dimensions of business-IT alignment. The 45th Hawaii International Conference on System Science Hawaii, United states (2012), 5053-506.

[10] Merali, Y., and McKelvey, B. Using Complexity Science to effect a paradigm shift in Information Systems for the 21 st century. Journal of Information Technology 21, 4 (2006), 211-215. 
[11] McKelvey, B., Tanriverdi, H., and Yoo, Y. Complexity and Information Systems. Research in the Emerging Digital World. MIS Quarterly (2016), 1-3.

[12] Tanriverdi, H., Rai, A., and Venkatraman, N. Research commentary-reframing the dominant quests of information systems strategy research for complex adaptive business systems. Information Systems Research 21, 4 (2010),822-834. [13] Amarilli, F., van Vliet, M., and Van den Hooff, B. Business IT Alignment through the Lens of Complexity Science. The 37th International Conference on Information Systems Dublin, Ireland (2016), 1-16.

[14] Peppard, J. and Campbell, B. The Co-evolution of Business/Information Systems Strategic Alignment: An Exploratory Study. Journal of Information Technology (2014), 1-51.

[15] Nassim, B., and Robert, F. IS Alignment improved with co-evolutionary principles: An Open Source approach. The 43rd Hawaii International Conference on System Sciences Hawaii, United States (2010), 1-10.

[16] Avison, D., Jones, J., Powell, P., and Wilson, D. Using and validating the strategic alignment model. The Journal of Strategic Information Systems 13, 3 (2004), 223-246.

[17] Coltman, T., Tallon, P., Sharma, R., and Queiroz, M. Strategic IT alignment: twenty-five years on. Journal of Information Technology 30, 2 (2015), 91-100.

[18] Aversano, L., Grasso, C., and Tortorella, M. A literature review of Business/IT Alignment Strategies. Procedia Technology 5 (2012), 462-474.

[19] Ullah, A. and Lai, R. A systematic review of business and information technology alignment. ACM Transactions on Management Information Systems 4, 1 (2013), 4.

[20] Luftman, J. Assessing business-IT alignment maturity. Strategies for information technology governance 4 (2004), 99.

[21] Luftman, J. and Kempaiah, R. An update on business-IT alignment:"A line" has been drawn. MIS Quarterly Executive 6, 3 (2007), 165-177.

[22] Trienekens, J. J., Kusters, R. J., and Cuenca, L. Measuring business-IT alignment, framework development and case study results. Information System Development Springer, Cham. 2014.

[23] Sabherwal, R., Hirschheim, R., and Goles, T. The dynamics of alignment: Insights from a punctuated equilibrium model. Organization Science 12, 2 (2001), 179197.

[24] Lyytinen, K., and Newman, M. Explaining information systems change: a punctuated socio-technical change model. European Journal of Information Systems 17, 6 (2008), 589-613.

[25] Wagner, H. T. Evolvement of business-IT alignment over time: A situated change perspective. The 47th Hawaii International Conference on System Sciences Hawaii, United States (2014), 4366-4375.

[26] Ohlsson, J., Han, S., Hultin, M., and Rosengren, B. How to Achieve Sustainable Business IT Alignment--Designing a Circular Organizational Structure at SAAB. The 49th Hawaii International Conference on System Sciences Hawaii, United States (2016), 5116-5125.

[27] Yoo, Y., Boland Jr, R. J., Lyytinen, K., and Majchrzak, A. Organizing for innovation in the digitized world. Organization science 23, 5 (2012), 1398-1408.
[28] Allen, P. M., and Varga, L. A co-evolutionary complex systems perspective on information systems. Journal of Information Technology 21, 4 (2006), 229-238.

[29] Tallon, P. P., and Pinsonneault, A. Competing perspectives on the link between strategic information technology alignment and organizational agility: insights from a mediation model. MIS Quarterly (2011), 463-486.

[30] Zhou, J., Fang, Y., and Zhao, P. Understanding IT Alignment Paradox: A Three-Way Interaction of Intellectual Alignment, Social Alignment, and Environmental Dynamism. The 38th International Conference on Information Systems Seoul, South Korea (2017), 1-18.

[31] Liang, H., Wang, N., Xue, Y., and Ge, S. Unraveling the Alignment Paradox: How Does Business-IT Alignment Shape Organizational Agility?. Information Systems Research 28, 4 (2017), 863-879.

[32] El Sawy, O. A., Malhotra, A., Park, Y., and Pavlou, P. A. Research commentary - seeking the configurations of digital ecodynamics: It takes three to tango. Information Systems Research 21, 4 (2010), 835-848.

[33] Peppard, J., and Breu, K. Beyond alignment: a coevolutionary view of the information systems strategy process. The 24th International Conference on Information Systems Seattle, WA (2003), 61-69.

[34] Amarilli, F., van Vliet, M., and Van den Hooff, B. An Explanatory Study on the Co-evolutionary Mechanisms of Business IT Alignment. The 38th International Conference on Information Systems Seoul, South Korea, (2017), 1-21.

[35] Parker, G. G. and Van Alstyne, M. W. Two-sided network effects: A theory of information product design. Management science 51, 10 (2005), 1494-1504.

[36] Gawer, A. Bridging differing perspectives on technological platforms: Toward an integrative framework. Research policy 43, 7 (2014), 1239-1249.

[37] Gawer, A. and Cusumano, M. A. Industry platforms and ecosystem innovation. Journal of Product Innovation Management 31, 3 (2014), 417-433.

[38] Tiwana, A., Konsynski, B., and Bush, A. Platform evolution: Coevolution of platform architecture, governance, and environmental dynamics. Information systems research 21, 4 (2012), 675-687.

[39] Adomavicius, G., Bockstedt, J. C., Gupta, A., and Kauffman, R. J. Making sense of technology trends in the information technology landscape: A design science approach. MIS Quarterly (2008), 779-809.

[40] Kahre, C., Hoffmann, D., and Ahlemann, F. Beyond business-IT alignment-Digital business strategies as a paradigmatic shift: A review and research agenda. The 50th Hawaii International Conference on System Sciences Hawaii, United States (2017), 1-10.

[41] Rajagopalan, N. and Spreitzer, G. M. Toward a theory of strategic change: A multi-lens perspective and integrative framework. Academy of management review 22, 1 (1997), 48-79.

[42] Bharadwaj, A., El Sawy, O.A., Pavlou, P.A., and Venkatraman, N. Digital business strategy: Toward a next generation of insights. MIS Quarterly 37, 2 (2013), 471-482. [43] Nan, N. and Tanriverdi, H. Unifying the role of IT in hyperturbulence and competitive advantage via a multilevel perspective of IS strategy. MIS Quarterly 41, 3 (2017), 937958. 
[44] Vidgen, R., and Wang, X. From business process management to business process ecosystem. Journal of Information Technology 21, 4 (2006), 262-271.

[45] Rowe F. What literature review is not: diversity, boundaries and recommendations. European Journal of Information Systems 23, 3 (2014), 241-255.

[46] Schwarz A, Mehta M, Johnson N. Understanding frameworks and reviews: a commentary to assist us in moving our field forward by analyzing our past. $A C M$ SIGMIS Database 38, 3 (2007), 29-50.

[47] Weeger, A., and Haase, U. How Contradictions Facilitate Evolutionary Transformation: an Exploration into the dynamics of Business-IT Alignment from the Perspective of Activity Theory.The European Conference on Information Systems Istanbul, Turkey (2016), 173-190.

[48] Zhang, N. N., Yu, A. Y., and Dong, X. A coevolutionary journey of strategic knowledge management alignment: a Chinese case. The 32th International Conference on Information Systems Shanghai, China, (2011), 1-19.

[49] Mitleton-Kelly, E., and Papaefthimiou, M. C. Coevolution and an enabling infrastructure: a solution to legacy? Systems engineering for business process change (2000), 164-181.

[50] Kim, R. M., and Kaplan, S. M. Co-Evolution in Information Systems Engagement: exploration, ambiguity and the emergence of order. The 3rd International Conference on Action in Language, Organisations and Information Systems (2005), 166-180.

[51] Kim, R. M., and Kaplan, S. M. Interpreting sociotechnical co-evolution: Applying complex adaptive systems to IS engagement. Information Technology \& People 19, 1 (2006), 35-54.

[52] Benbya, H., and McKelvey, B. Toward a complexity theory of information systems development. Information Technology \& People 19, 1 (2006), 12-34.

[53] Baker, J. and Singh, H. The Roots of Misalignment: Insights from a System Dynamics Perspective. The JAIS Theory Development Workshop Texas (2015), 1-37.

[54] Besson, P. and Rowe, F. Strategizing information systems-enabled organizational transformation: A transdisciplinary review and new directions. The Journal of Strategic Information Systems 21, 2 (2012), 103-124.

[55] De Haes, S. and Van Grembergen, W. An exploratory study into IT governance implementations and its impact on business/IT alignment. Information Systems Management 26, 2 (2009), 123-137.

[56] Agarwal, R. and Sambamurthy, V. Principles and models for organizing the IT function. MIS Quarterly 1, 1 (2002), 1-16.

[57] Yoo, Y., Henfridsson, O., and Lyytinen, K. Research commentary - the new organizing logic of digital innovation: an agenda for information systems research. Information systems research 21, 4 (2010), 724-735.

[58] Vessey, I. and Ward, K. The dynamics of sustainable IS alignment: The case for IS adaptivity. Journal of the Association for Information Systems 14, 6 (2013), 283-311.

[59] Cecez-Kecmanovic, D., and Kay, R. IS-organization coevolution: the future of information systems. The 22th International Conference on Information Systems New Orleans, LA (2001), 41-51.
[60] Teece, D.J. Dynamic Capabilities and Strategic Management: Organizing for Innovation and Growth: Organizing for Innovation and Growth. Oxford University, Oxford, U.K. 2009.

[61] Teece, D.J. The foundations of enterprise performance: dynamic and ordinary capabilities in an (economic) theory of firms. Acad. Manage. Perspect. 24, 4 (2014), 328-352.

[62] Yeow, A., Soh, C., and Hansen, R. Aligning with new digital strategy: A dynamic capabilities approach. The Journal of Strategic Information Systems 27 (2018), 43-58.

[63] Sandberg, J. Digital Capability: Investigating Coevolution of IT and Business Strategies. Umeå universitet. 2014.

[64] Chen, R. S., Sun, C. M., Helms, M. M., and Jih, W. J. K. Aligning information technology and business strategy with a dynamic capabilities perspective: A longitudinal study of a Taiwanese Semiconductor Company. International Journal of Information Management 28, 5 (2008), 366-378.

[65] Pelletier, C. and Raymond, L. The IT Strategic Alignment Process: A Dynamic Capabilities Conceptualization. Twentieth Americas Conference on Information Systems, Savannah (2014), 1-11.

[66] Karpovsky, A. and Galliers, R. D. Aligning in practice: from current cases to a new agenda. Journal of Information Technology 30, 2 (2015), 136-160.

[67] Wetering, R., Mikalef, P., and Pateli, A. A strategic alignment model for IT flexibility and dynamic capabilities: toward an assessment tool. Twenty-Fifth European Conference on Information Systems Guimarães, Portugal (2017), 1-19.

[68] Baker, J., Jones, D. R., Cao, Q., and Song, J. Conceptualizing the dynamic strategic alignment competency. Journal of the Association for Information Systems 12, 4 (2011), 299.

[69] Rai, A., and Tang, X. Information technology-enabled business models: a conceptual framework and a coevolution perspective for future research. Information Systems Research 25, 1 (2014), 1-14.

[70] Senge, P. M. The fifth discipline, the art and practice of the learning organization. Performance Improvement 30, 5 (1991), 37-37.

[71] Borshchev, A., and Filippov, A. From system dynamics and discrete event to practical agent based modeling: reasons, techniques, tools. The 22nd international conference of the system dynamics society Oxford, England (2004), 1-23.

[72] Merali, Y., Papadopoulos, T., Nadkarni, T. Information systems strategy: Past, present, future? The Journal of Strategic Information Systems 21,2 (2012), 125-153.

[73] Khan, M. A. An Integrated Framework to Bridging the Gap between Business and Information Technology-A Coevolutionary Approach. Canadian Journal of Pure and Applied Sciences 7, 3 (2013), 2611-2618.

[74] Bodhuin, T., Esposito, R., Pacelli, C., and Tortorella, M. Impact Analysis for Supporting the Co-Evolution of Business Processes and Supporting Software Systems. CAiSE Workshops (2004), 146-150.

[75] Kandjani, H., Tavana, M., Bernus, P., and Nielsen, S. Co-Evolution Path Model (CePM): Sustaining Enterprises as Complex Systems on the Edge of Chaos. Cybernetics and Systems 45, 7 (2014), 547-567. 